\title{
O raciocínio lógico e a lógica do raciocínio na pesquisa arqueológica
}

\author{
Julio Cezar Rubin de Rubin* \\ Marcos Antonio da Silva * * \\ Rosiclér Theodoro da Silva*
}

\begin{abstract}
RUBIN DE RUBIN, J.C.; SILVA, M.A.; SILVA, R.T. O raciocínio lógico e a lógica do raciocínio na pesquisa arqueológica. Revista do Museu de Arqueologia e Etnologia, São Paulo, 19: 13-20, 2009.
\end{abstract}

Resumo: $\mathrm{O}$ texto utiliza-se do raciocínio lógico e da lógica do raciocínio para estabelecer a relação entre a caracterização da área de pesquisa e as técnicas a serem utilizadas, determinadas em gabinete e laboratório, com as informações obtidas em campo. Para tanto, são apresentados dois estudos de casos de Pequenas Centrais Hidrelétricas do estado de Goiás, em que as informações de campo proporcionaram alteração em alguns procedimentos metodológicos e, principalmente, na contextualização envolvendo os vestígios culturais e as características/dinâmica das áreas. Alguns pressupostos da metodologia científica são inseridos na discussão, destacando a necessidade de o pesquisador conhecer diferentes técnicas de investigação e, dentre estas, aquela que melhor se adapta aos objetivos do projeto.

Palavras-chave: Geoarqueologia - Arqueologia - Metodologia de pesquisa.

\section{Introdução}

$\mathrm{E}$ nfocar o raciocínio lógico é condição para processar a investigação nos moldes do ensino da metodologia científica e o seu vínculo com os padrões que ditam, no âmbito da modernidade, como tal planejamento de pesquisa deve corresponder ao que se propõe verificar no momento da coleta de dados. Por outro lado, a realidade aponta, em campo, para

${ }^{*}$ ) Instituto Goiano de Pré-História e Antropologia Pontifícia Universidade Católica de Goiás. Rubin <rubin@ucg.br>; Silva <silva.rosicler@gmail.com>). $\left.{ }^{* *}\right)$ Unidade Acadêmico-Administrativa de Educação e Mestrado em Ecologia e Produção Sustentável. Pontifícia Universidade Católica de Goiás <marcos.edu@ucg.br>. a lógica do raciocínio, devido às condições vivenciadas e que se antepõem aos prévios estudos desenvolvidos em gabinete. Nesse caso, há de se considerar como se manifesta a experiência do investigador diante dos elementos que a realidade manifesta e, além disso, considerar o projeto de pesquisa mais como uma referência e menos como algo definitivo.

A Arqueologia é uma ciência que não pode ser limitada à, "camisa de força", ou seja, vinculada a modelos metodológicos preestabelecidos para apreender o campo da ação. A investigação in loco, condição inalienável deste conhecimento, tem exigências que extrapolam algumas estratégias constantemente utilizadas em outras áreas, em especial as relacionadas às ciências humanas e sociais. Haja vista que alguns investigadores a 
estas vinculados insistem em adotar técnicas tradicionais, porque consagradas na teoria, mas que estão em oposição à realidade, que cobra decisões por alternativas para cumprir com as eventuais exigências na coleta dos dados em processo. Ao se considerar que cada investigação tem um desenho ímpar, não estar disponível a inovações (que perpassa por adotar procedimentos que incluem a imaginação e outros instrumentos para se obterem as informações requeridas) se constitui como um fator limitante.

Isso não significa negar o valor da teoria, mas aprender a utilizar as alternativas metodológicas, em termos de técnicas e procedimentos que venham gerar condições, tanto no aprimoramento das prospecções (em termos técnicos e na economia de recursos), quanto nas teorias decorrentes e que passarão a integrar outras investigações. Não significa, ainda, traçar modelos engessados para a atuação do arqueólogo, mas a possibilidade de este ter como aliado uma ferramenta fundamental na sua atuação: a leitura e o registro do contexto cultural e ambiental.

A cultura material, objeto de estudo da Arqueologia, está inserida em um contexto ambiental dinâmico, seja em sítios abrigados seja em sítios a céu aberto, exigindo do arqueólogo uma percepção a respeito das características culturais e ambientais que envolvem seu objeto de estudo. Essa percepção é que vai estabelecer a relação cultura material/registro estratigráfico/ dinâmica da área, fundamental para a pesquisa arqueológica.

Esse artigo utiliza-se da análise de dois casos para ressaltar a significância de tais procedimentos, integra atividades de gabinete e campo, aponta lacunas e falhas, e demonstra a linha de raciocínio que fundamentou as pesquisas.

\section{A realidade como objeto da investigação na Arqueologia}

Pode-se afirmar que a Arqueologia constitui um campo ainda em processo de difusão em todo o território brasileiro, em virtude de uma prática tardia e de pouca penetração no ambien- te acadêmico e do aspecto "fantasioso" de que por vezes se reveste o trabalho do arqueólogo (aventureiro e desbravador). Portanto, urge destacar o que melhor caracteriza esse conhecimento: a sua inestimável condição de estudar as ocupações e suas relações com os comportamentos humanos contextualizados (Migliacio 2008). Nas palavras da autora, fica evidente a necessidade da percepção a respeito da dinâmica da paisagem e do diálogo entre o raciocínio lógico e a lógica do raciocínio. A investigação arqueológica, ao lançar mão de métodos e técnicas de análise de outros ramos do conhecimento, tem contribuído de sobremaneira com resultados fundamentais para o saber científico (Ponte 1995). E essa direção, aberta à multiplicidade de usos metodológicos de variados campos científicos, representa o grande trunfo dessa ciência.

Sobre a lógica da investigação, Yuni e Urbano (2006) reconhecem a dimensão estratégica como condição inalienável do processo, em especial no trabalho de campo, e isso implica saber optar por metodologias mais convenientes nesse momento, ou seja, escolher quais decisões propiciam apreender a realidade investigada e permitem estabelecer a relação com o desenho teórico que norteia o estudo. Por isso, o investigador deve previamente conhecer os diversos procedimentos e técnicas, para selecionar o que melhor permite atingir seus objetivos. Além disso, deve reconhecer que a má teoria corresponde àquela que está contida nela mesma (Demo 1988), mas não se deve esquecer de um componente: a contextualização expressa em múltiplas variáveis.

Há mais de trinta anos, Castro (1977) chamava a atenção sobre algumas vezes utilizarse, para efeito de estabelecer uma fronteira entre a ciência e a não-ciência, da exigência de uma lógica cuidada, e que isso não poderia se constituir em critério. O que se deveria evitar seria a formação de juízos de valor em relação aos fatos. E acrescentava que o método científico é muito exigente e proibitivo, os modelos teóricos são ora inexistentes, em alguns estudos, ora inadequados, e que não podem gerar respostas, o que implica a necessidade de decidir por uma alternativa de prática in loco. Reconhecia, nesse sentido, que aprender ciência é também desenvolver a 
capacidade de atuar de forma circunstancial e conforme a realidade que se apresenta.

O raciocínio lógico, na pesquisa arqueológica, implica a utilização de uma série de procedimentos, tanto em campo quanto em gabinete, que permitem alcançar os objetivos do projeto, assunto amplamente tratado, principalmente em manuais de arqueologia ou, de forma geral, em livros de metodologia científica. A lógica do raciocínio aflora, quando as evidências de campo são confrontadas com o planejamento estabelecido em gabinete, indicando ou não alterações nos procedimentos metodológicos. A grande questão que cerca esse diálogo é a capacidade de leitura da paisagem ou do meio ambiente, que envolve o sítio arqueológico, por parte do pesquisador.

Note-se que a teoria expressa conceitos abstratos - independentemente de ser construída na realidade e, nesse sentido, passa a ser generalizada - e que a adoção formal ocasiona, por vezes, certo distanciamento da realidade (Demo 1988). Portanto, conforme Demo (1988), é possivel verificar que nenhuma prática esgota a teoria e que a importância desta mais se afirma quando aquela a complementa, na sua demonstração. Entretanto, não se descarta a condição de que a prática é uma versão, porque exige a interpretação. Em síntese, estabelecer uma devida relação entre uma e outra é a condição para melhor conhecer.

Nesse devir, Yuni e Urbano (2006) enunciam critérios básicos que integram aspectos da lógica interna do método científico, responsáveis pela estrutura do que se pretende conhecer (paradigma norteador, particularidades do objeto de estudo, definições prévias e teoria considerada). No que se refere ao fator externo, este se mostra na oportunidade, no acesso à informação e nos recursos (logísticos, de infraestrutura, humanos e outros). A relação entre estes fatores é que propicia a condição para que se processe a investigação a partir dos dados empíricos.

Conforme recomenda Demo (1991), a relação entre a teoria e a prática deve ultrapassar o academicismo e a "sofisticação" preconizada por alguns instrumentos. Santos (2002) propõe a reflexão sobre "[...] a idéia, hoje partilhada por muitos, de estarmos em uma fase de transição. Portanto, finalmente a urgência de dar resposta a perguntas simples, elementares, inteligiveis". Ou seja, excluir algumas indagações que se distanciam da lógica científica (Castro 1977) e partir das experiências para atingir a realidade. Isso não significa negar a racionalidade de outras formas de apreensão do conhecimento (Santos 2002), mesmo aquelas que não "pautarem pelos princípios epistemológicos e pelas regras metodológicas".

O trabalho de prospecção envolve uma série de atividades pré-campo e em campo que, infelizmente, não é utilizada por alguns pesquisadores, principalmente em projetos de arqueologia de contrato, os quais basicamente se restringem à caracterização da área, por meio de mapas temáticos (de litologia, solos, vegetação, geomorfologia e outros), e, algumas vezes, à fotointerpretação e à análise de imagens de satélite. Alunos de graduação em Arqueologia que, durante a sua formação, se limitam à participação em projetos dessa natureza, adotam esse procedimento indiscriminadamente. Castro (1977) lembra a recomendação de Kaplan de que a experiência promove a apreensão do mundo, o que é devidamente enfatizado por Demo (1988), para quem a verdadeira mestra da ciência é a realidade.

A investigação decorre de modelos conceituais e de referentes empíricos (Yuni, Urbano 2006), portanto, o investigador precisa definir as unidades a serem observadas, além dos critérios e os procedimentos para desenvolver o estudo. Isso implica, também, considerar a representatividade dos resultados obtidos para que se caracterizem como elementos vinculados à produção científica. É nessa direção que o investigador precisa definir as unidades a serem observadas, os critérios e os procedimentos para desenvolver o estudo. Implica, também, considerar a representatividade dos resultados obtidos para que se caracterizem como elementos vinculados à produção científica. Nesse sentido, as opções metodológicas dão o tom para, no caso da Arqueologia, uma vez adotadas técnicas de outras áreas do conhecimento e conferidos outros olhares sobre os objetos de estudo, mais uma vez se defrontar com a necessária formação para a pesquisa, para não incorrer em vieses. É 
preciso reconhecer que somente é possivel improvisar a partir de um conhecimento prévio de alternativas e de suas viabilidades em termos de promover o conhecimento.

Burgess (1997), sobre essa questão, adianta que é comum, nos estudos de campo, a adoção de diversas técnicas e procedimentos, em especial os que se relacionam uns com os outros, desde que se considerem as vantagens e seus opostos. Importante é que estes sejam devidamente adequados ao tipo de problema que se pretende resolver. Nesse caso, exige-se uma postura flexível do investigador sobre a utilização e o devido estabelecimento da relação entre os dados empíricos e a teoria norteadora, que, de fato, caracteriza uma estratégia de investigação e que denota a lógica do raciocínio. A exigência é que se mantenha presente o todo da investigação e cada vez mais se distancie do limitado rigor científico (Santos 2002), se a pretensão é apreender a realidade e também contribuir com alternativas metodológicas, o que melhor caracteriza o conhecimento em uma perspectiva da ciência-processo.

\section{Estudos de caso}

\section{PCH Mosquitão municípios de Iporá e} Arenópolis, sudoeste do estado de Goiás

A área diretamente afetada pelo empreendimento construído no rio Caiapó é de $2,9 \mathrm{~km}^{2}$. A empresa contratante não dispunha de mapas temáticos (litologia, pedologia, geomorfologia e cobertura vegertal), os mapas do RADAMBRASIL eram em escalas incompatíveis com a área de pesquisa $(1: 1.000 .000)$ e o mapa topográfico na escala $1: 1000.000$ era também desfavorável para a abordagem proposta. Desta forma, a alternativa adotada para a caracterização ambiental foi a utlização de imagens de satélite na escala 1: 120.000. Ressalta-se que as fotografias aéreas na escala 1:60.000 também foram descartadas por não estarem disponíveis. Com o mapa topográfico e a imagem de satélite, estabeleceu-se o zoneamento da área, levando-se em consideração a declividade do terreno e a ocupação do solo, instrumento que norteou o levantamento sistemático realizado em toda a área, utilizandose de transects (Silva; Almeida 2005).

Dentre diversos aspectos, o zoneamento indicou um terraço aluvial delimitado pelo canal fluvial e por uma encosta com declividade média de 35\% na margem direita, próximo ao eixo da barragem. As informações sobre a geologia da área obtida no Relatório Ambiental Simplificado (CPE, 2002) indicavam afloramentos de granito na encosta. Estabeleceu-se que em campo seria realizada uma vistoria na encosta, à procura de abrigos, cuja presença poderia estar associada à alta declividade de terreno, a mesma que impedia a realização dos transects no segmento. Seria executado, também, um sistema de sondagens no terraço, em solo aluvial, com profundidade ultrapassando a $1 \mathrm{~m}$, pois, pela natureza do terraço, poderiam ser encontrados vestígios culturais associados a fácies deposicionais resultantes da dinâmica fluvial. Nesse aspecto, a equipe de campo foi informada quanto às principais características do ambiente fluvial e da variedade de vestígios culturais possíveis de serem identificados.

A imagem de satélite indicou, ainda, a presença de estradas, sedes de fazenda abandonadas, áreas de pastagem e de lavoura, ou seja, áreas impactadas por atividades antrópicas. Nas encostas, verificou-se a presença de processos erosivos e, com isso, uma possível deposição de solo sobre a região aluvial, fato que deveria ser confirmado em campo, visando também ao ajuste na profundidade da sondagem. A equipe de campo também foi preparada para identificar processos erosivos de pequeno porte, como sulcos e calhas, além de solos e sedimentos transportados. A área diretamente afetada foi bem caracterizada em gabinete e a equipe preparada para o desenvolvimento das atividades programadas, mas, sem perder de vista que as observações adquiridas em campo poderiam alterar os procedimentos preestabelecidos, ou seja, o diálogo entre o raciocínio lógico e a lógica do raciocínio.

Em campo, verificou-se que o terraço era parcialmente estrutural, com um segmento aluvial, e que havia grande quantidade de grânulos e seixos de calcedônia arredondados e esféricos, distribuídos na encosta e no terraço, 
realidade que levou ao primeiro confronto entre o raciocínio lógico e a lógica do raciocínio e à formulação das primeiras hipóteses sobre os grânulos e seixos, que poderiam ser decorrentes de deposição fluvial ou transportados da encosta. Na seqüência, contatou-se, por informações orais e por observações in loco de algumas pequenas feições, que a área fora objeto de atividades de garimpo. Uma nova hipótese foi formulada: os grânulos e seixos resultavam de atividades de garimpo. Uma questão importante se inseriu no contexto: o grau alteração/ transformação da paisagem em conseqüência de atividade antrópica. Portanto, os procedimentos estabelecidos em gabinete tiveram de ser revistos. Após alguns dias em campo, chegou-se a algumas conclusões:

- os depósitos aluviais e o solo in situ estavam perturbados por atividade antrópica e pela dinâmica atual do rio;

- a distribuição dos grânulos e dos seixos não estava relacionada com os depósitos caóticos do garimpo. Em alguns segmentos verificou-se uma granocrescencia à montante em relação à encosta. Os grânulos e seixos estavam relacionados ao transporte a partir da encosta;

- o granito que aflorava na encosta apresentava grande quantidade de amígdalas arredondadas, preenchidas por calcedônia, e a alteração da rocha tinha dispersado na encosta e no terraço grande quantidade desse material;

- as sondagens seriam realizadas em solo aluvial (terraço aluvial), cambissolo (terraço e encosta) e litólico (encosta).

De posse dessas informações e conhecendo a dinâmica natural da área, além do histórico da ocupação, foi realizado o sistema de sondagem sistemática, com sondagens a profundidades diferenciadas no cambissolo, no solo aluvial e no solo litólico, o que, neste último, não ultrapassou $0,10 \mathrm{~m}$. A intensidade da ação antrópica na área foi acentuada, podendo-se afirmar que não houve qualquer região que não tenha sido afetada, mesmo aquelas que atualmente apresentam mata ciliar.
As sondagens realizadas no terraço estrutu$\mathrm{ral} /$ aluvial evidenciaram instrumentos líticos lascados, distribuídos em superfície por uma área de aproximadamente $20 \mathrm{~m}^{2}$, eventualmente confeccionados no local ou ali depositados pelo rio Caiapó ou pela dinâmica superficial.

\section{PCH Mambaí II município de Damianópolis, nordeste do estado de Goiás}

As atividades desenvolvidas em gabinete, para o levantamento do potencial arqueológico da área diretamente afetada pela PCH Mambaí, com $0,29 \mathrm{~km}^{2}$, foram realizadas utilizando-se das bases cartográficas fornecidas pela contratante: $\mathrm{O}$ mapa do empreendimento, escala 1:10.000, o mapa topográfico na escala 1:100.000 e a imagem de satélite. Consideraram-se o tipo e a espessura do solo, além da dinâmica superficial, fatores importantes em uma área acidentada, com vales encaixados e encostas íngremes. As fontes disponíveis eram de escalas incompativeis com a pesquisa arqueológica e essa dificuldade foi atenuada pelas dimensões reduzidas da área de estudo (Barberi et al. 2004; Silva, Rubin 2008).

Foram identificadas áreas favoráveis à ocupação, em segmentos da encosta com baixa declividade e junto às margens do rio Corrente. Nos segmentos de alta declividade, foram realizadas vistorias, objetivando a identificação de abrigos. Posteriormente, no decorrer do levantamento sistemático, se constatou que alguns fatores relacionados à dinâmica da área e que estavam relacionados com a pesquisa arqueológica não foram considerados. Algumas áreas foram novamente prospectadas.

O solo in situ nos segmentos das encostas com baixa declividade estava capeado por sedimentos transportados de montante por meio de deslizamentos e escorregamentos, cujas cicatrizes estavam visíveis nas encostas. Essa realidade implicou que sondagens complementares fossem realizadas, procurando ultrapassar o solo transportado, objetivo alcançado na quase totalidade dessas ações. A espessura média do solo transportado era de $0,60 \mathrm{~m}$, por outro lado, a espessura média do solo in situ amostrado foi de $0,50 \mathrm{~m}$. 
As áreas de baixa declividade junto à margem do rio Corrente, interpretadas inicialmente como terraço aluvial, constituíam base da encosta com baixa declividade e, principalmente, barra arenosa e planície de inundação, resultantes da dinâmica erosivo-deposicional do rio Corrente. Foram realizadas sondagens tanto no pequeno dique marginal, quanto na planície de inundação subatual. As sondagens nas áreas aluviais alcançaram uma profundidade média de $1,0 \mathrm{~m}$.

Durante a etapa de levantamento sistemático foram encontradas algumas lascas arqueológicas, (classificação de campo), associadas a depósitos residuais de canal (grânulos, seixos, blocos e matacões). Posteriormente, em laboratório, verificou se tratarem de lascamentos naturais, possivelmente relacionados ao processo de transporte.

A exemplo do caso anterior, a área de implantação da PCH Mambaí II exigiu ajustes entre os trabalhos de gabinete e de campo. Também nesse caso, a pesquisa de campo foi realizada seguindo a metodologia proposta, procurando relacionar variáveis ambientais, dinâmica superficial e contexto cultural. Ocorre que o levantamento sistemático identificou uma problemática subdimencionada no planejamento - os escorregamentos/deslizamentos e, com isso, a espessura do solo transportado sobre a encosta, além das características da área deposicional junto à margem do rio. Os ajustes foram realizados sem qualquer dificuldade para desenvolvimento das atividades de campo. A utilização de fotografias aéreas atuais em escala adequada poderia ter identificado as feições erosivas, porém as mesmas não se encontravam disponíveis.

\section{Conclusão}

O raciocínio lógico conduz a uma série de procedimentos metodológicos voltados aos objetivos de um projeto de pesquisa. Nos casos apresentados, em que a pesquisa tem uma clara abordagem geoarqueológica, a contextualização sítio/meio ambiente necessita de profissionais especializados para compor um grupo interdisciplinar. A pesquisa arqueológica poderia ser desenvolvida sem as hipóteses e considerações apresentadas. A questão é que a dinâmica da área tem uma relevância extraordinária tanto no levantamento do potencial arqueológico quanto nas considerações que envolvem os vestígios culturais encontrados. Que diferença teria para a pesquisa arqueológica se esse raciocínio não fosse adotado?

Depende do ponto de vista. Um profissional que não considerasse as variáveis ambientais relevantes também teria executado o sistema de sondagem. Por outro lado, os procedimentos adotados permitiram caracterizar as variáveis ambientais e antrópicas, abordar alguns processos responsáveis pela evolução da paisagem e corrigir as técnicas de prospecção. Todos esses fatores conjugados permitiram, ainda, que os trabalhos de sondagem fossem executados com técnicas apropriadas para cada segmento da paisagem, o que é relevante nas conclusões da pesquisa, ao contribuir para uma contextualização de meio ambiente/sítio arqueológico.

Indubitavelmente o custo financeiro de uma abordagem contextualizadora é mais elevado, mas produz resultados significativos à pesquisa arqueológica, pois aborda os diversos aspectos que podem estar relacionados com a formação, a contextualização e a conservação do sítio. Um levantamento sistemático realizado com uma técnica que, por exemplo, adote uma profundidade padrão de $0,50 \mathrm{~m}$, ao final terá deixado uma série de lacunas nos resultados, pois pode, em muitos casos, não ter atingido o solo de ocupação. Isso, somado aos problemas relacionados com as amostragens, aumentaria ainda mais a imprecisão dos resultados.

A gama de técnicas e procedimentos adotados, sua disponibilidade e a multiplicidade de usos metodológicos de inúmeros ramos científicos caracterizam significativamente a Arqueologia. Portanto, em muitas ocasiões, são necessárias decisões decorrentes da experiência do corpo de pesquisadores, para que os resultados melhor se manifestem e para que se viabilize a produção de novas possibilidades teóricas.

Impraticável pensar na investigação arqueológica sem considerar o contexto no momento da obtenção das informações. Nessa direção, a eliminação de limites - desde a formação de juízos de valor e a desvinculação de "cabrestos" metodológicos - exigirá a adoção de modelos teóricos que permitam uma postura flexível, devido às exigências de tomar decisões em função 
das circunstâncias e das condições em que se apresenta a realidade. Desse modo, é possivel reconhecer que o raciocínio lógico na pesquisa arqueológica adotará procedimentos de campo e laboratório conforme os objetivos do projeto.

A lógica do raciocínio se atém às evidências de campo e à relação com o planejamento prévio, indicando as alterações requeridas em termos de metodologia, a partir da capacidade da equipe pesquisadora e das características do ambiente onde se situa o sítio arqueológico. Reconhecer a dimensão abstrata dos conceitos e não distanciar-se da realidade é condição de uma prática que requer a interpretação e implica estabelecer uma adequada relação entre o proposto, o observado e o caracterizado. Portanto, deve-se considerar a estrutura da investigação e as condições para a sua realização e, nesse caso, não atrelar a investigação a tão-somente os rigores acadêmicos e a ditadura dos instrumentos, descontextualizados da realidade.

Investigar significa não dispensar o emprego de outros recursos, independentemente das orientações preconizadas nas regras e na epistemologia. Nesse sentido é que se coloca a exigência, nessa área do saber, de uma capacitação voltada para a apreensão da realidade a partir das experiências práticas. Aprender a ter autonomia para adotar diferentes opções metodológicas exige uma prévia formação para saber o momento e as condições em que isso deve ocorrer.

Os casos apresentados ressaltam a importância de uma boa interpretação da área a ser pesquisada antes do início das atividades de campo e, acima de tudo, que esta deve ser vista como uma referência substancial para o bom desenvolvimento da pesquisa, porque pode ser alterada ou complementada.

Os procedimentos apresentados procuraram ilustrar a relação entre o raciocínio lógico e a lógica do raciocínio que remete o pesquisador, conforme as variáveis observadas em campo, a ajustar a metodologia, portanto, a furtar-se de cabrestos preestabelecidos. Ressalte-se que os procedimentos adotados, nos casos apresentados, dependeram da participação efetiva, na equipe de gabinete e campo, de profissionais das geociências, capazes de interpretar a paisagem, ou de arqueólogos com formação em geoarqueologia, cujo enfoque científico - proporcionado pelas medidas tomadas em campo, desvinculadas de absolutos foi capaz de aproximar mais a realidade que se queria conhecer a padrões investigativos alternativos que, longe de serem intuitivos, resultaram em contribuições para captar inserção, ou não, de cultura nos ambientes investigados.

RUBIN DE RUBIN, J.C.; SILVA, M.A.; SILVA, R.T. The logical reasoning and the logic of the reasoning in archaeological research. Revista do Museu de Arqueologia e Etnologia, São Paulo, 19: 13-20, 2009.

\begin{abstract}
The text uses logical reasoning and the logic of reasoning to establish the relation between the characterization of the research area and the techniques to be used, worked out in laboratories and offices, with the information collected in the field. For this, two small Hydroelectric Plants case studies, in the State of Goiás, are presented. Their field information had provided changes in some methodological procedures and, mainly, in the contextualization involving the cultural vestiges and the characteristics/dynamic of the areas. Some assumptions on the scientific methodology are brought into the discussion, emphasizing the necessity of the researcher knowing different research techniques and, amongst these that one that best fits the project aims.
\end{abstract}

Keywords: Geoarchaeology - Archaeology - Research methodology. 


\section{Referências bibliográficas}

BARBERI, M.; SILVA, R. T.; RUBIN, J. C. R.

2004 Programa de Levantamento Sistemático dos Patrimônios Arqueológicos Préhistórico, Histórico e Histórico-Cultural na Área Diretamente Impactada pela PCH Mambaí II - Etapa 1 (Levantamento Sistemático). Goiânia, Lithotec Consultoria e Assessoria Ltda, Instituto Goiano de Pré-História e Antropologia.

BURGESS, R.G.

1997 A pesquisa de terreno: uma introdução. Oeiras, Portugal: Celta.

CASTRO, C. M.

1977 A prática da pesquisa. São Paulo: McGrawHill do Brasil.

CPE CONSÓRCIO PRODUTORES DE ENERGIA

2002 Relatório Ambiental Simplificado - RAS. Goiânia, Consórcio Produtores de Energia, CTE Engenharia Ltda.

DEMO, P.

1988 Introdução à metodologia científica. 2. ed. São Paulo: Atlas.

1991 Pesquisa: princípio científico e educativo. 2. ed. São Paulo: Cortez.

MIGLIACIO,M.C.

2008 Patrimônio arqueológico e memória. Disponivel em: http:www.geografia.ufmt.br/ eventos/engeo2004/mesas/ seminário010.htm. Acesso em: 17 abril.
PONTE, M.S.

1995 A arqueologia e o arqueólogo neste final de século. Revista de Guimarães, Guimarães, Portugal, 105: 59-62.

SANTOS, B.S.

2002 Um discurso sobre as ciências. 13. ed. Portugal: Afrontamento.

SILVA, R. T., ALMEIDA, M.B.

2005 Programa de Levantamento Sistemático dos Patrimônios Arqueológicos Pré-histórico, Histórico e HistóricoCultural na Área Diretamente Afetada pela PCH Mosquitão e pela Linha de Transmissão de $138 \mathrm{Kw}$ Mosquitão/SE Iporá. Muncípios de Iporá e Arenópolis/GO. Goiânia, Fundação Aroeira, Instituto Goiano de Pré-História e Antropologia.

SILVA, R.T.; RUBIN, J.C.R.

2008 Projeto de Monitoramento Arqueológico na Área Diretamente Impactada pela PCH Mambaí II. Relatório Parcial. Goiânia, Ambiental Consultoria e Assessoria, Instituto Goiano de PréHistória e Antropologia.

YUNI, J.; URBANO, C.

2006 Técnicas para investigar: recursos metodológicos para la preparación de proyectos de investigación. v. 2.2 ed. Argentina: Brujas. 